\section{Avulsion of Deep MCL at the Proximal Attachment to the Medial Femoral Condyle}

\begin{abstract}
The medial collateral ligament (MCL) is the most commonly injured ligament of the knee joint. Proximal superficial medial collatera ligament $(\mathrm{MCL})$ tears occur more frequently than do distal ones. Isolated avulsion of deep MCL is not well described in literature.

We report a 61-year-old man with a valgus injury of his left knee joint after a MVA. Radiological and magnetic resonance imaging of the affected knee joint revealed a complete avulsion fracture of proximal attachment of deep part of the medial collateral ligament Such a pattern isolated deep MCL avulsion is rare.
\end{abstract}

\section{Introduction}

The medial collateral ligament (MCL) is the prime static stabilizer of the medial side of the knee joint. The superficial part of the MCL originates from the femoral condyle and epicondyle and inserts just below the tibial articular surface. The deep part is divided into meniscofemoral and meniscotibial portions that are attached to femoral and tibial site deep to the superficial part of the MCL.

Ossification/calcification around the medial femoral condyle has been known as Pellegrini-Stieda Syndrome (PSS) for almost 100 years [1]. Depending on shape and site, four different types have been described.

In contrast to the ACL, the MCL has shown excellent healing capability in both animal and clinical studies [2]. Although in mild cases conservative treatment is often successful, patients with more significant bone formation and persistent symptoms require surgical excision $[3,4]$

However, not all calcification or ossification around medial condyle is PSS. Variant of has been reported where the MCL was avulsed from both the proximal and distal attachments with a partial tear in the substance of the ligament [5]. We report a case of femoral avulsion of deep MCL. This injury was mistaken for a PellegriniStieda lesion by the radiologist. The flake bone visible corresponded to the attachment of the deep MCL [Meniscofemoral Avulsion].

\section{Case Report}

A 61-year-old truck driver man presented with a valgus injury to the left knee joint when involved in a truck accident. He was driving his truck, he ran off the road and when he got out of the truck he had a laceration in his head. He put his foot down and his knee almost gave way. There was a previous history of pain related to osteoarthritis in his both knees. He went to a District health Hospital. He had a cut on his head stitched up. He had a swollen left knee and was able to walk with a limp. Physical examination revealed moderate haemarthrosis with medial soft tissue swelling and significant tenderness along the

\section{Journal of \\ Orthopedics \& Rheumatology}

\author{
Vishal Pai ${ }^{*}$ and Vasu Pai \\ ${ }^{\prime}$ Advanced Orth Trainee Registrar, Alfred Hospital, Melbourne, \\ Australia \\ ${ }^{2}$ Orthopaedic Surgeon, Bonefix, Auckland, New Zealand \\ *Address for Correspondence \\ Pai VS, D Orth, MS, MCh, FRACS, CIME, Orthopaedic Surgeon, Auck- \\ land, New Zealand, Tel: +64 210234 0544; Fax: 00619 2675370; E-mail: \\ vasuchitra@gmail.com \\ Submission: 12 August, 2016 \\ Accepted: 12 September, 2016 \\ Published: 22 September, 2016 \\ Copyright: () 2016 Vishal P, et al. This is an open access article \\ distributed under the Creative Commons Attribution License, which \\ permits unrestricted use, distribution, and reproduction in any medium, \\ provided the original work is properly cited. \\ Reviewed \& Approved by: Dr. Elliott H. Leitman, Christiana Care Health \\ System, USA
}

course of the MCL. He had an X-ray and was told that there was an avulsion injury of the MCL from the medial femoral condyle (Figures 1 and 2). He was admitted overnight and was discharged the following day with crutches, touch weight bearing in a Zimmer brace. After six weeks he had an intense physiotherapy and slowly his brace was weaned off with increasing weight bearing.

He was referred for persistent symptoms in the knee [L]. His main at his presentation to our clinic was lateral knee pain with occasional medial knee pain. The knee did not lock. He occasionally had night pain.

Clinically John stood with a varus left knee and walked with a lateral thrust. He had a full, active straight leg raise and pain at end range of flexion. He had significant pseudo-laxity medially. There was

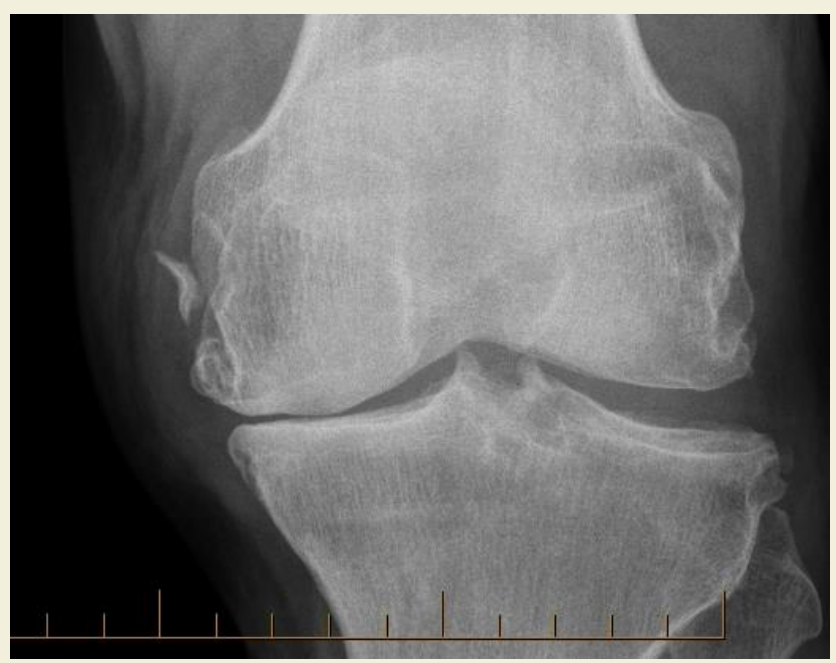

Figure 1: $X$ ray: Antero-posterior radiograph of the left knee shows an elliptic bone fragment arising from the medial surface of the medial condyle. 


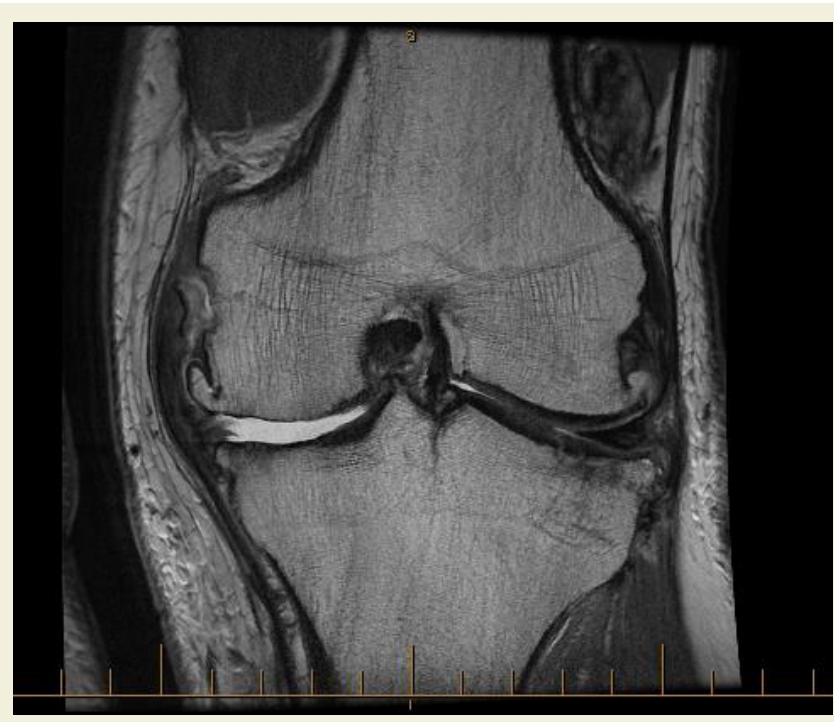

Figure 2: T1 MR scans of the left knee showing avulsion of deep MCL at the proximal attachment to the medial femoral condyle.

no significant posterior sag or anterior drawer, and no significant laterally based symptoms. He has mild joint line tenderness on the medial side.

His MRI scan showed full thickness articular surface loss with joint line wear on the medial side, which was consistent with his pre-existing osteoarthritis. There appeared to have been an avulsion fracture of the deep MCL (meniscofemoral component) from the medial condyle of the femur. There was evidence of early healing. Superficial MCL was intact but thickened.

He had a significant varus deformity with medial joint line pain. His MRI scan confirms loss of medial joint space. The only surgical option here would be to contemplate a total knee joint replacement. This was not required at the time of assessment as there was minimal impairment. He was asked to return to work as he was in fit state to drive a vehicle.

The medial collateral ligament injury proximally, therefore, seems somewhat trivial and had healed well clinically and on an MRI

\section{Discussion}

The MCLis a commonkneeinjuryand is usually related to sportslike hockey, skiing and football [6,7]. The mechanism of injury is typically a contact valgus load on the lateral side of the knee with the foot planted; however, non-contact external rotation valgus injuries also common.

Warren has described the majority of the basic anatomy $[8,9]$. The superficial MCL is the primary static medial stabilizer of the medial knee. It originates from the medial epicondyle and inserts on the medial aspect of the proximal tibial $5-7 \mathrm{~cm}$ below the joint line. The most common type of injuries is isolated to the superficial MCL with Grade I and II laxity associated with failure occurring at its femoral attachment. Less commonly Grade III injuries are seen which are associated with concomitant ACL and meniscal tears in $80 \%$ of cases [10]. The most severe injuries are those with multiple ligament involvement, may require operative repair or augmentation on an acute basis.

In a cadaver sectioning study, the superficial MCL limits valgus and external rotation forces. On the other hand, the deep MCL and the posterior oblique ligament failed to show a significant contribution to stability [9]. The location of maximum strain of the MCL is at femoral attachment, which is a common site of failure of superficial MCL.

The deep MCL is the thick ligament, which is also known as middle capsular ligament. It extends from medial aspect of the medial condyle and inserts just below the tibial articular margin. In between its bony insertion, it is attached to the periphery of the medial meniscus. The portion of deep MCL above the meniscus is menisco-femoral portion and below is meniscotibial portion of deep MCL. Avulsion of the menisco-femoral ligament is rare and we could not find such a lesion reported in the literature including in a review article of avulsion fractures of the knee $[11,12]$. It appears these deep fibers are tight in knee in flexion and a valgus rotation injury in a flexed knee can cause injury to deep fibers of MCL.

Unlike the superficial MCL, the exact location of injuries of the deep MCL and posterior oblique ligament were found to be difficult to palpate because of their deep seated position. Isolated injury to deep medial collateral ligament can be treated nonsurgically in a functional knee brace. This was adopted in the above case report and knee was stable for valgus both in 0 degrees and 90 degrees.

Soft tissue calcification in the proximity of the femoral medial epicondyle, on X-ray examinations does not necessarily translate to Pellegrini-Stieda lesion. Periarticular calcification around the knee has rarely been described [13]. We have now discussed an even rare case of avulsion fracture of menisco-femoral part of the deep MCL.

\section{References}

1. Mendes LF, Pretterklieber ML, Cho JH, Garcia GM, Resnick DL, et al. (2006) Pellegrini-Stieda disease: a heterogeneous disorder not synonymous with ossification/calcification of the tibial collateral ligament-anatomic and imaging investigation. Skeletal Radiol 35: 916-922.

2. Indelicato PA (1995) Isolated medial collateral ligament injuries in the knee. $J$ Am Acad Orthop Surg 3: 9-14.

3. Wang JC, Shapiro MS (1995) Pellegrini-Stieda syndrome. Am J Orthop (Belle Mead NJ) 24: 493-497

4. Theivendran K, Lever CJ, Hart WJ (2009) Good result after surgical treatment of Pellegrini-Stieda syndrome. Knee Surg Sports Traumatol Arthrosc 17: 12311233.

5. Naik AM, Rao SK, Rao PS (2007) Medial collateral ligament avulsion from both tibial and femoral attachments: a case report. J Orthop Surg (Hong Kong) 15: 78-80.

6. Phisitkul P, James SL, Wolf BR, Amendola A (2006) MCL injuries of the knee: current concepts review. lowa Orthop J 26: 77-90.

7. Miyamoto RG, Bosco JA, Sherman OH (2009) Treatment of medial collateral ligament injuries. J Am Acad Orthop Surg 17: 152-161.

8. Warren LF, Marshall JL (1979) The supporting structures and layers on the medial side of the knee: an anatomical analysis. J Bone Joint Surg Am 61: 56-62.

9. Warren LA, Marshall JL, Girgis F (1974) The prime static stabilizer of the medical side of the knee. J Bone Joint Surg Am 56: 665-674. 
Citation: Pai VS, Pai V. Avulsion of Deep MCL at the Proximal Attachment to the Medial Femoral Condyle. J Orthopedics Rheumatol. 2016 ; $3(1)$ : 3.

\section{ISSN: 2334-2846}

10. Wilson TC, Satterfield WH, Johnson DL (2004) Medial collateral ligament "tibial" injuries: indication for acute repair. Orthopedics 27: 389-393.

11. Gottsegen CJ, Eyer BA, White EA, Learch TJ, Forrester D (2008) Avulsion fractures of the knee: imaging findings and clinical significance. Radiographics 28: $1755-1770$
12. NarvaniA,MahmudT, LavelleJ,WilliamA(2010)Injurytotheproximaldeepmedial collateral ligament: a problematical subgroup of injuries. J Bone Joint Surg $\mathrm{Br}$ 92: 949-953.

13. Song K, Dong J, Zhang Y, Chen B, Wang F, et al. (2013) Arthroscopic management of calcific tendonitis of the medial collateral ligament. Knee 20: 6365. 